\title{
REVIEW
}

\section{Review of Osteosarcoma and Current Management}

Ryan A. Durfee · Maryam Mohammed · Hue H. Luu

Received: August 5, 2016 / Published online: October 19, 2016

(C) The Author(s) 2016. This article is published with open access at Springerlink.com

\section{ABSTRACT}

Osteosarcoma is the most common primary malignancy of bone in children and young adults. This tumor has a very heterogeneous genetic profile and lacks any consistent unifying event that leads to the pathogenesis of osteosarcoma. In this review, some of the important genetic events involved in osteosarcoma will be highlighted. Additionally, the clinical diagnosis of osteosarcoma will be discussed, as well as contemporary chemotherapeutic and surgical management of this tumor. Finally, the review will discuss some of the novel approaches to treating this disease.

Keywords: Limb preservation surgery; Osteosarcoma; Review; Targeted therapy

Enhanced content To view enhanced content for this article go to http://www.medengine.com/Redeem/D1E6 F06013338352.

R. A. Durfee · M. Mohammed · H. H. Luu ( $\varangle)$

Department of Orthopaedic Surgery and

Rehabilitation, University of Chicago, Chicago, IL, USA

e-mail: hluu@bsd.uchicago.edu

\section{OSTEOSARCOMA}

Osteosarcoma (OS) is a high-grade primary skeletal malignancy characterized by spindle cells of mesenchymal origin depositing immature osteoid matrix $[1,2]$. With an annual incidence rate of 3.1 cases per million in the US, OS accounts for less than $1 \%$ of all newly diagnosed cancers in adults and $3-5 \%$ of those in children, but it is the most common primary malignancy in adolescents outside of leukemia and lymphoma [3]. Although rare overall, OS is the most common primary malignancy of bone in children [3-5]. OS incidence is distributed bimodally across age. An initial peak is observed between the ages of 10 and 14 years during the pubertal growth spurt, and is followed by a smaller second peak after the age of 60 years [6]. OS develops in adolescents most often at the metaphysis of lower extremity long bones ( $\sim 75 \%$ of cases), and these findings suggest a relationship between the hormonal changes of puberty and/or physiologic bone growth and the pathogenesis of OS [4, 6-8]. While long bones of the extremities continue to be the most common site for OS after the age of 60 years, 
they no longer account for the majority of cases due to an increase in the diversity of primary tumor sites. Craniofacial and axial tumors increase in frequency with age, accounting for $40 \%$ of all OS cases after 60 years of age, compared to less than $12 \%$ before the age of 24 years [6]. Juxtacortical osteosarcomas that occur along the surface of bones are usually lower grade, although there are some exceptions [9].

\section{Compliance with Ethics Guidelines}

This article is based on previously conducted studies and does not involve any new studies of human or animal subjects performed by any of the authors.

\section{PREDISPOSING CONDITIONS AND RISK FACTORS FOR OS}

\section{Genetics of OS}

Phenotypic risk factors for OS are related to physiologic growth and include both a tall height and a high birth weight [10]. The vast majority of cases are the result of sporadic mutations, but loss of tumor suppressor function is commonly identified in OS and represents a critical step in its pathogenesis [11-13]. Overall, there is no unifying genetic event that leads to the development of OS. In addition to somatic mutations, there are a few well-identified syndromes that predispose to OS, and these are usually discussed to highlight some of the sentinel genetic events that are involved in pathogenesis.

Li-Fraumeni syndrome (LFS) is the most common syndrome predisposing to pediatric sarcomas and involves a germline mutation of the TP53 gene. TP53 encodes for p53, a master transcription factor regulating expression of
DNA repair genes and initiating apoptosis when damage is irreparable [14]. Loss of this tumor suppressor function predisposes to a multitude of malignancies, and an estimated $30 \%$ of patients with LFS develop OS during their lives $[15,16]$. Although LFS is rare, damage to the p53 pathway is not. Mutations at TP53 represent the most frequently identified genetic alterations in human cancers. Somatic loss of p53 has also been identified in $18-26.5 \%$ of sporadic cases of OS $[8,17]$.

Retinoblastoma is another condition commonly identified to predispose to OS. The retinoblastoma protein $\mathrm{pRb}$ (encoded by $R B 1$ ) binds the E2F family of transcription factors and halts progression through the G1 phase of the cell cycle [18]. Loss of pRb induces unregulated cell cycle progression. Germline loss of $R B 1$ in 13q14 microdeletion syndrome (hereditary retinoblastoma) is associated with an increased risk for retinoblastoma and, to a lesser degree, soft-tissue sarcomas, melanoma, and OS [19-21]. Sarcomas are the most common secondary tumors in retinoblastoma patients, representing $60 \%$ of cases, and may be due in part to the use of radiation in the treatment of retinoblastoma $[21,22]$. Loss of $\mathrm{pRb}$ is common in sporadic cases of OS as well ( $>60 \%$ of cases in one series), and is predictive of unfavorable outcomes [23, 24]. Loss of other genes in this pathway are functionally equivalent to loss of RB1 and have been identified in OS tumors lacking $R B 1$ alterations $[25,26]$.

RecQ helicases are members of a conserved family of proteins that unwind double-stranded DNA prior to replication. Loss of RecQ helicases is an inheritable risk factor for OS [27, 28]. Germline mutations in genes in the RecQ family give rise to the rare autosomal recessive cancer predisposition disorders (e.g., Bloom's syndrome, Werner's syndrome, and Rothmund-Thomson 
syndrome), which are all associated with increased incidence of OS [29].

In addition to genetic alterations due to chromosomal instability and loss of tumor suppressor genes, OS can also have disruptions in major signaling pathways, creating a bone microenvironment that promotes proliferation and metastasis. The TGF- $\beta$ proteins are part of a superfamily of five isoforms (TGF- $\beta 1-5$ ) and the bone morphogenic proteins (BMP1-15) [30]. Skeletal tissue harbors the largest reserve of TGF- $\beta$ [31]. TGF- $\beta$ has a broad range of activities, including stimulating mesenchymal cell growth, immunosuppression, and enhancing extracellular matrix production; TGF- $\beta 1$ has a mitogenic effect on OS cell lines [32].

Alterations in the insulin-like growth factor-I (IGF-RI) receptor pathway have been identified in the development of OS [33-40]. Upon binding the IGF-RI, IGF-I/II activate downstream PI3K/Akt/mTOR and MAPK/ERK cascades promoting proliferation, migration, and survival. Burrow et al. found overexpression of IGF-IR, IGF-I, and IGF-II in a significant proportion of 48 OS primary tumors, with no difference in expression between primary and metastatic samples [38]. In preclinical studies, OS proliferation was enhanced by IGF-I/II and inhibited when IGF-IR was silenced by monoclonal antibodies, RNA interference, or microRNA [39, 40]. Increased IGF-1 expression leads to more aggressive phenotypes in vitro and is a negative prognosticator when found in primary tumors $[36,37]$. mTOR, a downstream target in the IGF-I/II pathway, is an attractive target in many cancers, and recent efforts have attempted to target this area in OS [41].

Metastatic OS has its own set of identifiable genetic alterations that allow tumor cells to migrate into the bloodstream, avoid apoptosis and immune destruction, and adhere and proliferate in distant tissues. Promotion of the Wnt/B-catenin and src pathways have been implicated in the migration of tumor cells into the circulation, and upregulation of the Notch1 and Notch2 receptors has been identified in highly metastatic OS specimens. The Fas/Fas ligand pathway is a death receptor pathway that is often downregulated in OS [42, 43]. Besides triggering apoptosis, Fas receptors also function to target the cell for elimination by natural killer (NK) cells. Elimination of this pathway allows OS cells to both avoid apoptosis and evade the immune system, and it is not surprising that samples from pulmonary OS metastases have been shown to be Fas negative [44, 45]. Once in target cells, tumor growth and progression is assisted by growth factors and angiogenic enzymes such as PDGF-R, VEGF, EGFR, and IL-8. The src pathway is again active at this step and is responsible for hyperproliferation of tumor cells and induction of neovascularity $[46,47]$.

As the science of molecular genetics advances, so does our understanding of osteosarcoma. A recent genome-wide association study of 941 cases of OS and 3291 controls was able to identify 2 loci with genome-wide significance, one at $6 \mathrm{p} 21.3$ in the glutamate receptor metabotropic 4 (GRM4) gene, and another in a gene desert on 2p25.2 [48]. The GRM4 gene is involved in cyclic AMP signaling and may have important interactions in bone metabolism. Another multi-institution genome-wide scan in 935 patients with metastatic OS found significance in a mutation of the NF1B gene. The mutation decreased NF1B activity, leading to increased OS cell migration, proliferation, and colony formation [49].

\section{Risk Factors for Secondary OS}

Secondary OS can develop following malignant degeneration of benign bone lesions or 
exposure to ionizing radiation [50-52]. It accounts for one-third of cases in patients $>65$ years old [6]. Geographic variation in the incidence of risk factors for secondary OS, namely radiation exposure and Paget's disease, has been used to explain OS incidence rates in the elderly [10]. The etiology of secondary OS in the setting of radiation is likely due to DNA damage from the ionizing radiation. In Paget's disease, the pathogenesis to OS development is not well understood.

\section{CLINICAL PRESENTATION AND MANAGEMENT OF OSTEOSARCOMA}

Conventional OS is the most common histologic type and accounts for approximately $75 \%$ of all cases [53]. These tumors represent the classic form of OS: a high-grade mass of malignant mesenchymal cells with osteoid production and local tissue invasion. Conventional osteosarcomas are further classified into osteoblastic, chondroblastic, or fibroblastic types, depending on which matrix-producing cells dominate, but generally behave similarly in regards to appearance and prognosis [54]. Other high-grade central osteosarcomas include telangiectatic, giant cell-rich, small cell, and epithelioid variants, each with characteristic histology and small differences in survival [55]. A low-grade intramedullary type termed low-grade central osteosarcoma (LCOS) has a much lower rate of metastasis and greater overall survival $[54,55]$.

OS can originate along the cortex or periosteum as well. The most common of these juxtacortical lesions is parosteal sarcoma, which constitutes about $1-6 \%$ of all OS cases [54]. These lesions are found on the metaphyseal regions of long bones, typically the distal femur, and have a "stuck on" appearance. They are slow-growing and low-grade in comparison to conventional OS, and histologic examination shows well-differentiated fibrous stroma with osseous components. They may have a cartilage cap and can be confused with osteochondromas, but will not have the characteristic cortical-medullary continuity characteristic of those benign lesions [56]. Periosteal sarcomas are another type of juxtacortical OS with a similar "stuck on" appearance, but they exhibit more aggressive characteristics on radiographs and histology. These tumors represent mid-grade lesions, but rarely metastasize when treated appropriately [57]. Finally, high-grade surface OS is the most aggressive type and has a course similar to conventional high-grade OS [9].

\section{Presenting Signs and Evaluation}

Patients with OS often present with nonspecific complaints, including pain in the affected area. Pain during sleep, enlarging mass, and worsening pain without clear signs of infection or injury are particularly worrisome signs. Physical exam findings may reveal a palpable mass, restricted joint motion, pain with weight bearing, or localized warmth/ erythema. An estimated 5-10\% of patients will present with a pathological fracture as their first sign of illness [58]. The traditional signs of cancer-weight loss, malaise and fever-are usually only present in advanced disease and are not sensitive signs in children [59].

Workup should begin with orthogonal X-ray imaging of the affected extremity. Radiographs will typically demonstrate a poorly marginated or moth-eaten appearance of the bone with mixed amounts of cloudy mineralized matrix and areas of bone resorption. Alternatively, a 
cartilage or fibrous matrix may be present, or there may be tremendous bone resorption, depending on the subtype [56]. If the lesion has an associated soft tissue mass, a discontinuous or broken periosteal reaction is usually present (Fig. 1). Lab work is nondiagnostic, but high levels of alkaline phosphatase (ALK-P) and lactate dehydrogenase (LDH) have been shown to predict a poorer prognosis [60-63]. Advanced imaging is best accomplished with magnetic resonance imaging (MRI) and should be performed for the entire bone. MRI will clearly demonstrate the extent of the bone marrow invasion, the presence and size of any soft-tissue mass, and the relationship to surrounding vital structures (Fig. 2). Tumors are hypointense on T1, hyperintense on T2 and STIR imaging, usually exhibit mixed heterogeneity and surrounding peritumoral edema, and show abundant enhancement with contrast administration. It is important to image the entire bone involved to detect potential skip metastases and accurately plan resection and reconstruction efforts. Generally speaking, computed tomography (CT) is inferior to MRI, unless further information is needed regarding cortical integrity or the presence of fracture [54].

When a diagnosis of malignancy is suspected, a biopsy is required for tissue confirmation. This can usually be accomplished with a core needle biopsy using either ultrasound or CT guidance. The specialist performing the biopsy should communicate with the treating physician to plan the incision such that the biopsy tract can be easily removed with the tumor. Multiple cores can be obtained from the same incision, which increases the accuracy of diagnosis [56]. If needle biopsy is insufficient, an open biopsy can be performed, but it should be done
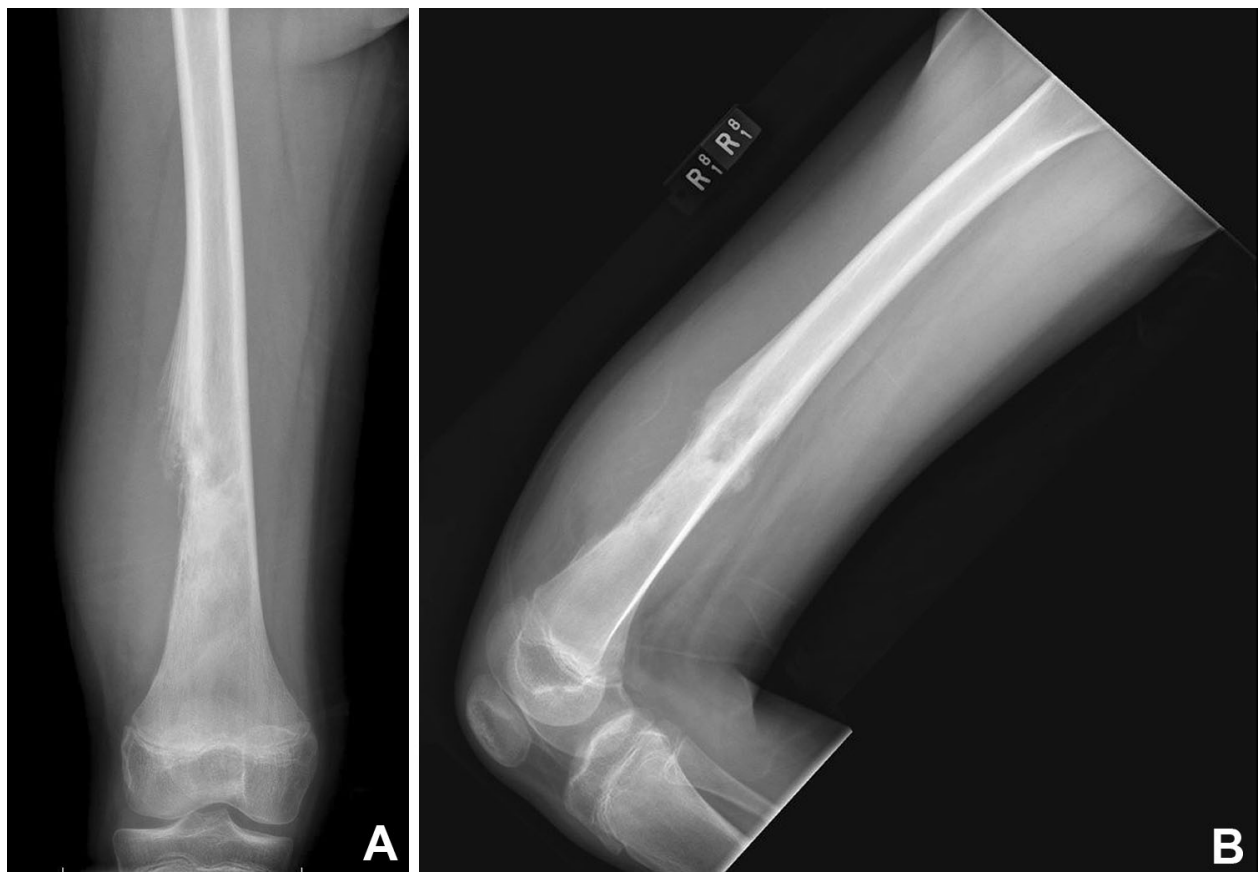

Fig. 1 AP (a) and lateral (b) X-rays of an 11-year-old patient with an osteosarcoma of the distal femur. Note the wide zone of transition, discontinuous periosteal reaction, and areas of increased mineralization 

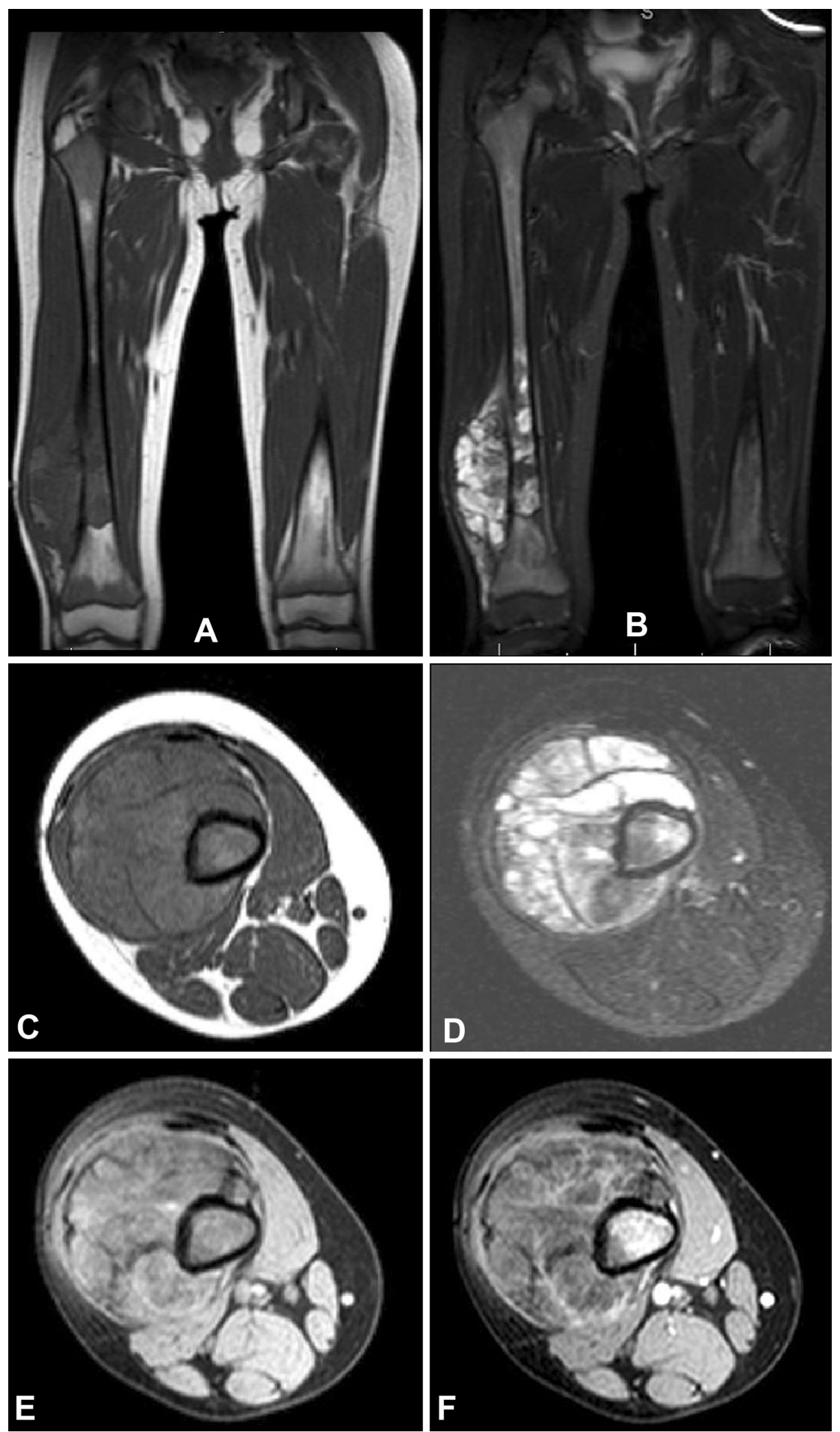
4 Fig. 2 MRI images from the patient in Fig. 1. a Coronal images showing the extent of the marrow abnormality and the soft-tissue mass which appears hypointense on T1 imaging. b STIR imaging illustrating the reaction zone of peritumoral inflammation. c, d Axial images through the tumor reveal a large soft tissue mass with surrounding edema. Pre- (e) and post-contrast (f) axial images show areas of enhancement in the bone and soft tissue, corresponding to sites of increased metabolic activity

through a small incision, with meticulous hemostasis. It is best performed by the surgeon who will carry out the final resection [64]. There is some evidence that not all needle biopsy tracts need to be resected [65], but an open biopsy tract should always be removed along with the tumor. At our institution, needle biopsy tracts are removed along with the final resection to prevent any chance of recurrence from residual tumor cells.

\section{Histologic Findings}

Histologic examination of conventional OS demonstrates malignant spindle or polyhedral mesenchymal cells with pleomorphic nuclei, scattered mitotic figures, and varying levels of anaplasia (Fig. 3). Immature and disorganized osteoid production is a characteristic hallmark and must be present for diagnosis. Conventional osteosarcomas may have a matrix dominated by osseous, cartilaginous, or fibrous elements, and are further subtyped depending on which of these matrix cells dominate. Other types of OS will show similar high-grade morphology along with areas of abundant giant cells, small cells, or epithelioid morphology, but must also contain osteoid somewhere in the sample. Lower-grade central and surface OS will demonstrate woven microtrabeculae of bone within a bland to moderately cellular fibrous stroma $[54,55]$.

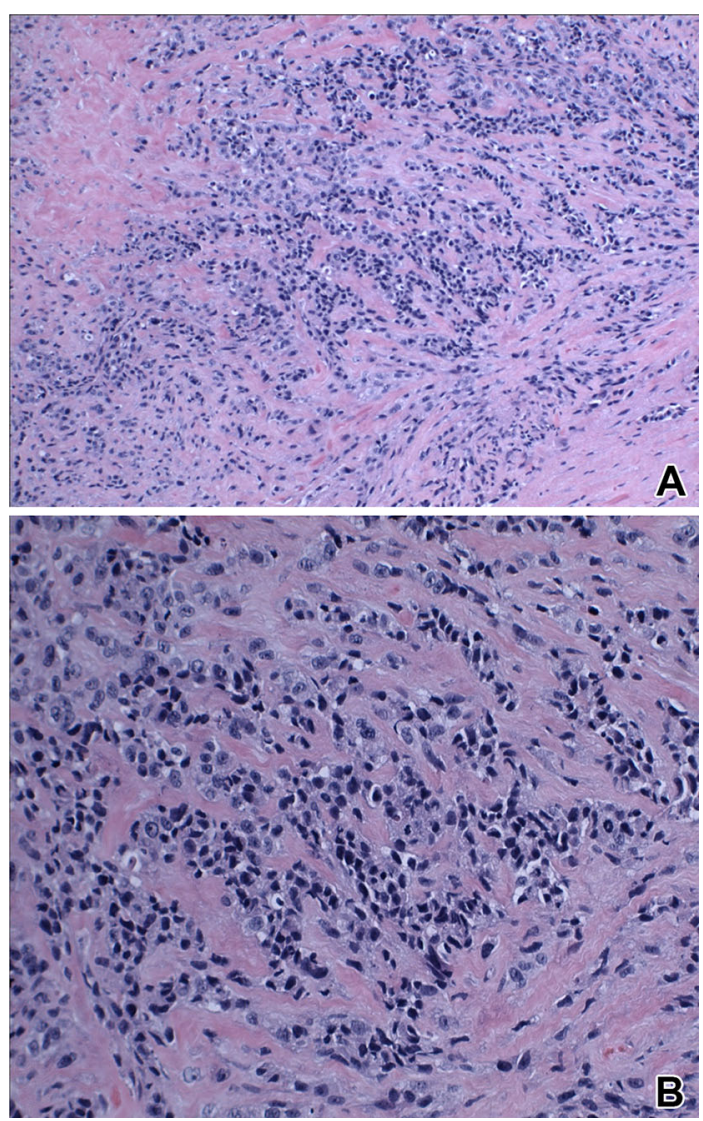

Fig. 3 Medium-power (a) and high-power (b) microscopic images of an osteosarcoma specimen, showing high cellularity, nuclear polymorphism, atypia, and disorganized osteoid production

\section{Staging}

Staging is important for detecting metastasis, establishing prognosis, and determining appropriate medical therapy and surgery $[53,63,66]$. Since over $75 \%$ of metastases involve the lungs, all patients with bone sarcoma should receive a CT scan of the chest $[67,68]$. At presentation, $20 \%$ of patients have metastatic disease detectable with current CT imaging. However, the majority of metastatic disease is microscopic, and it is estimated that another $60 \%$ of patients have micrometastatic disease [69-71]. A bone scan or positron emission tomography (PET) scan is recommended to detect metastatic bone and 

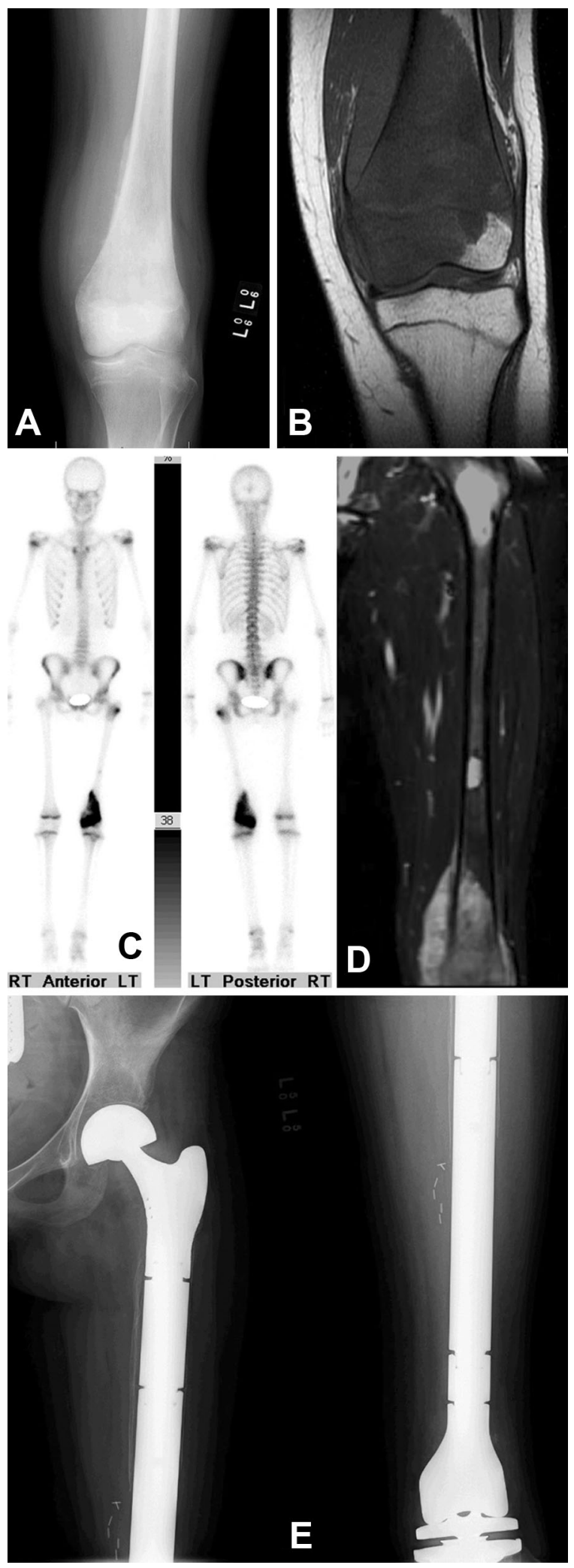

4 Fig. 4 X-ray (a) and MRI (b) of the distal femur of a 13-year-old girl, showing a large solitary lesion. However, staging with bone scan (c) and MRI (d) revealed additional skip metastasis in her ipsilateral femur diaphysis and peritrochanteric area that was not detected with initial imaging. The presence of the skip metastases changed the surgical plan from a distal femur resection to an entire femur resection and reconstruction (e)

soft-tissue disease (Fig. 4). Bone scan is more cost-effective and superior to PET for bony disease, but PET allows for better detection in soft tissue, and includes the chest and abdomen. Both are effective scanning techniques; the choice made usually varies by institution. An additional advantage of PET is that it may be able to identify tumors with higher metabolic activity and, therefore, higher-grade malignancies [72, 73]. Finally, if not already available, an MRI of the entire bone involved is important to rule out any skip metastases, which must be addressed with primary resection and predict a poor survival [74].

The two staging systems currently employed for staging OS are the Enneking system and the AJCC (Tables 1, 2). Enneking was the first to organize bone sarcoma into a comprehensive staging system, and the AJCC later used these principles to develop its own staging system with nomenclature similar to that used for other cancers. Both use histological grade and the presence/absence of metastases and differ in their evaluation of the size of the primary tumor. The Enneking system makes a distinction between whether the mass is intracompartmental or has become extracompartmental, while the AJCC system uses tumor size $(<8$ or $>8 \mathrm{~cm})$ to determine a T1 from a T2 tumor. Despite these differences, most tumors will be a similar stage in both systems, as the major driver of prognosis is the 
Table 1 Enneking MSTS staging system

\begin{tabular}{llll}
\hline Stage & Grade & Size & Metastasis \\
\hline IA & Low & T1-intracompartmental & M0—none \\
IB & Low & T2-extracompartmental & M0—none \\
IIA & High & T1-intracompartmental & M0—none \\
IIB & High & T2-extracompartmental & M0—none \\
III & Any & Any & M1-regional or distant \\
\hline
\end{tabular}

Table 2 AJCC staging system for bone sarcoma

\begin{tabular}{lllll}
\hline Stage & Grade $(\mathbf{G})$ & Size $(\mathbf{T})$ & Lymph node $(\mathbf{N})$ & Metastasis $(\mathbf{M})$ \\
\hline IA & G1-low & T1 $<8 \mathrm{~cm}$ & N0-none & M0-none \\
IB & G1-low & T2 $>8 \mathrm{~cm}$ & N0-none & M0-none \\
IIA & G2-high & T1 $<8 \mathrm{~cm}$ & N0-none & M0-none \\
IIB & G2-high & T2 $>8 \mathrm{~cm}$ & N0-none & M0-none \\
III & Any G & Any T & Skip metastasis & Skip metastasis \\
IVA & Any G & Any T & N0-none & M1-lung metastasis \\
IVB & Any G & Any T & N1-lymph node metastasis or N0 & M1-non-lung metastasis \\
\hline
\end{tabular}

presence of metastases, which both systems define similarly [75].

\section{Treatment}

Prior to the advent of chemotherapy, OS was almost a universally fatal disease. Patients with metastasis at diagnosis would typically survive only months, and those with localized disease would soon develop metastatic spread, despite radical and disabling surgical procedures. In the 1970s, Jaffe published the first significant success of chemotherapy, showing that methotrexate was a useful agent to manage metastases in advanced disease [76]. As new cytotoxic agents were discovered, the use of chemotherapy blossomed, but the practice remained controversial until a landmark study in 1985 which showed an increase in 6-year survival from 11 to $61 \%$ with the addition of multi-agent chemotherapy [69]. A study performed during the same time period at Memorial Sloan Kettering found similar increases in survival with chemotherapy that was given before surgery (neoadjuvant), showing that it was safe to delay surgery for treatment [77]. The authors preferred neoadjuvant chemotherapy because it allowed more time to fabricate endoprosthetic devices, decreased tumor size, and permitted an analysis of the surgical specimen for its response to chemotherapy [66].

\section{Chemotherapy}

Today, most OS patients receive neoadjuvant chemotherapy, followed by surgical resection of all detectable disease and a regimen of adjuvant chemotherapy postoperatively [78]. The current regimen of methotrexate, adriamycin, and 
cisplatin (MAP) has become standard in North America and Europe [66, 79]. This is typically started after pathological diagnosis and staging studies have been completed, and continues for a period of 6-8 weeks depending on the institution [80]. Some centers will also add ifosfamide with or without etoposide, but this increases the toxicity of therapy, and recent randomized clinical trials have failed to show a survival advantage [81, 82]. Unfortunately, many agents are limited by their toxicity profile, and some side effects, such as adriamycin-induced cardiomyopathy, can be permanent [83]. There is a dose effect on treatment response, but recent research has shown that high-dose chemotherapy does not increase survival when compared to less toxic moderate doses [84]. Much research has been focused on changing chemotherapy to improve survival in patients with a poor histologic treatment response, but this has so far been unsuccessful [85, 86]. Resistance to chemotherapy is often multifactorial and an area of much recent research [87]. Chemotherapy has little effect on lower-grade types of OS, such as parosteal and periosteal sarcoma, and these tumors have good rates of survival without systemic therapy $[9,57,88]$. Radiation treatment is rarely included as an adjuvant, but has been used in unresectable cases [89-91].

\section{Surgery}

Regardless of the chemotherapy regimen, surgical removal of all evidence of disease remains critical to obtaining a remission and improving patient survival. Patients will undergo resection of the OS tumor by amputation or limb salvage surgery techniques as well as resection of any metastases if possible. All tumors should be removed with a wide margin to prevent residual disease; the adequacy of this margin is critical in preventing recurrences [92]. Recurrent disease is closely linked to a poor prognosis and the risk of metastatic disease. Following resection, pathological specimens are examined to see the effect that chemotherapy has had on the tumor. A necrosis rate of $\geq 90 \%$ is considered a "good response," and these patients will have a better prognosis than those with less than 90\% necrosis. Besides its prognostic value, histological response has been used to guide therapy. Patients with a good response are restarted on their preop chemo regimen, while patients with a poor response may be switched to a different combination of drugs. Despite some favorable results in smaller studies, no regimen has been shown to be superior in a poor responder, but this is an area of continued research [86]. Chemotherapy can usually be resumed 2-3 weeks after surgery, once the wound is healed $[80,93]$.

Historically, amputation was believed to be necessary to control local disease, but that has changed in recent decades, as advances in chemotherapy, imaging, and reconstruction techniques have made limb salvage surgeries more feasible [94, 95]. Today, about $85 \%$ of high-grade appendicular OS cases can be successfully resected and reconstructed with preservation of the affected limb and its function $[94,95]$. In limb preservation surgery, the tumor is removed while maintaining a wide cuff of tissue around the tumor when possible, but allowing more narrow margins around vital neurovascular structures. Careful dissection preserves limb function but still removes all disease safely.

Theoretically, limb preservation increases the rate of local recurrence, but in experienced hands it can be performed with little or no increase in local recurrence compared to 
amputation [95-99]. In a report of 560 patients from the Rizzoli Institute, there was no difference in local recurrence between patients treated with amputation and those with limb preservation surgery [96]. In the Rizzoli study, recurrence correlated closely with margin status and tumor grade, showing that the quality of resection and underlying tumor biology are the most important factors in recurrence, not surgery type. The safety of limb preservation has been confirmed many times, with the most recent being a meta-analysis including over 1300 patients [96, 100-102]. Local recurrence was equal for amputation and limb salvage, and patients with limb salvage actually had a higher 5-year survival [100]. For these reasons, amputation is generally reserved only for those tumors in which a resection to disease-free margins is not possible without creating a nonfunctional limb [94].

Limb preservation surgery can be complex. There are a number of options for reconstruction. These include manufactured endoprosthetic devices, bulk allografts, biological constructs, or combinations of these elements. Endoprosthetic replacement of tumor defects has greatly increased over the past few decades and is now the surgery of choice in many centers (Fig. 5). Most are modular, allowing a degree of customization that can be adjusted intraoperatively to match the anatomic needs of each patient. They provide excellent reconstruction options for metaphyseal tumors, as the adjacent joint can be reconstructed, and are usually stable postoperatively for early mobilization and weight bearing. The main drawbacks of these devices are a lifelong infection risk, since the reconstruction is nonbiological, as well as complications from wear, hardware breakdown, and the risk of eventual mechanical failure. Implant survivorship is typically over $80 \%$ at
5 years and drops to $60 \%$ at 10 years. A recent British study with over 15 years of follow-up found that $42 \%$ of patients with endoprosthetic reconstruction required revision or amputation within 10 years, with $51 \%$ of these revisions being due to mechanical failure and 33\% due to infection [103]. Given a long enough lifespan, most survivors of OS with endoprosthetic reconstruction will have to undergo one or more revision surgeries [104].

Bulk allograft reconstruction involves matching the resected specimen with a donor graft of comparable size and shape. Successful outcome is contingent on a biological union between the host and implanted bone; rigid fixation is paramount for this process to occur. Over time, these implants slowly undergo variable rates of osseous and vascular integration by the body and have a theoretical advantage of being a permanent replacement for the resected bone [105]. Other advantages include higher rates of soft-tissue integration and customizability for nonstandard resections. Unfortunately, failure rates can be as high as $17-20 \%$ due to infection, nonunion, or implant fracture. Additionally, union rates are decreased by radiotherapy, chemotherapy, and poor nutritional states, one or more of which is usually present in patients with OS. The risk of failure is highest in the first 3 years but plateaus thereafter. Approximately $75 \%$ of patients with a graft present for over 5 years report good or better outcomes as far out as 20 years after surgery [105].

When used for reconstructing joint surfaces, osteoarticular allografts develop subchondral collapse, with the resulting arthritis quickly leading to early failure. However, they can be combined with manufactured joint implants, resulting in an allograft-prosthetic composite. The outcome is an implant with the advantages (and disadvantages) of both an allograft and an 


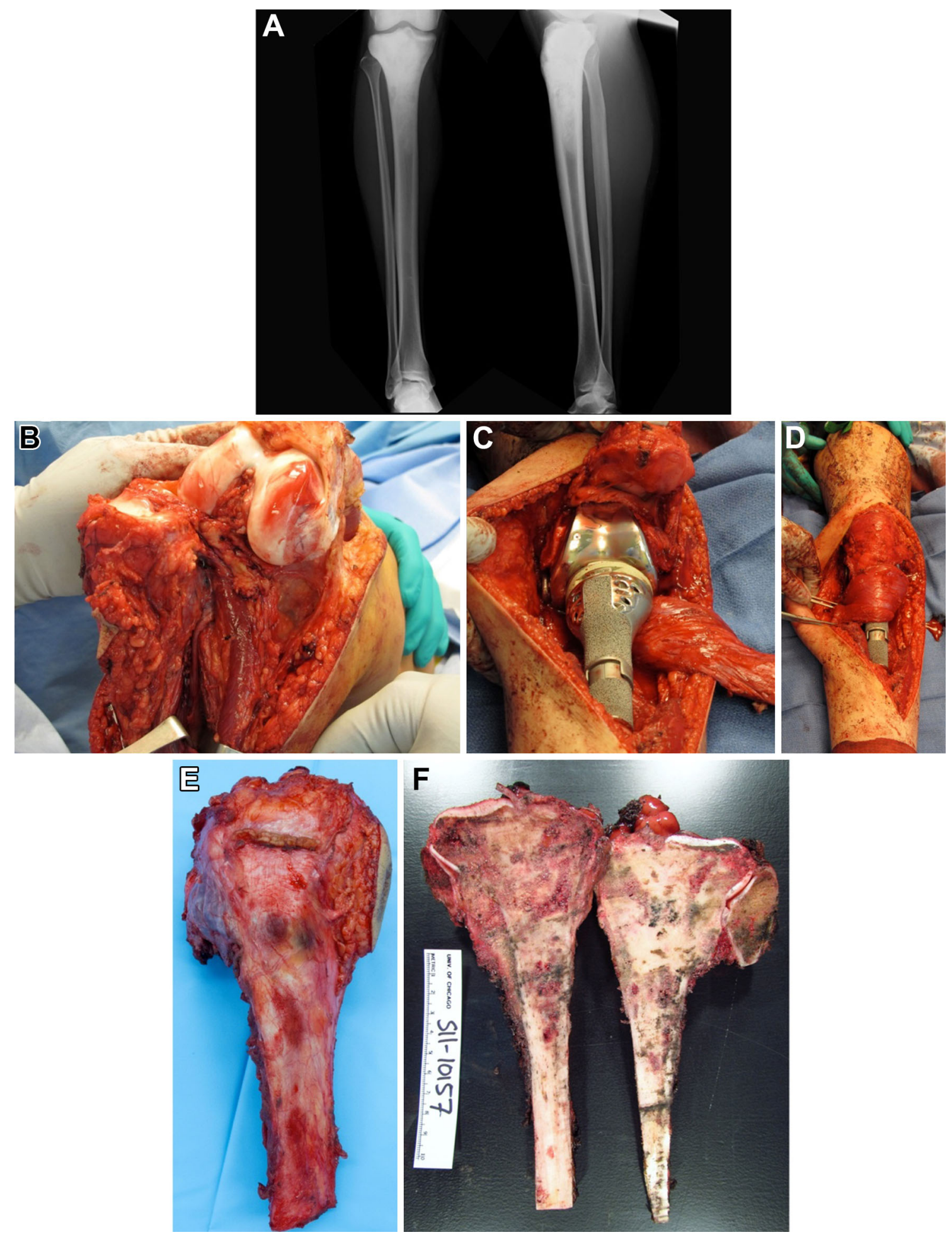


4 Fig. 5 A 22-year-old male with an osteosarcoma of the proximal tibia. XR images (a) show an aggressive lesion of the proximal tibia with abundant osseous matrix. Resection of the tumor mass was performed with care taken to spare the neurovascular bundle (b), and then the defect was reconstructed with a proximal tibia endoprosthesis $(\mathbf{c})$ and a medial gastrocnemius muscle flap for soft-tissue coverage (d). Resected tumor specimen (e, f) and gross pathology examination

endoprosthesis. The allograft side allows for a stronger and more complete reconstruction of the periarticular soft-tissue envelope and incorporates into the patient's host bone, while the prosthetic side creates a stable and predictable joint articulation. These implants represent a high degree of complexity for the surgeon, but have been shown by several centers to provide a stable reconstruction with similar failure rates to other methods [106, 107].

Most OS cases occur in younger patients, many of which have active growth plates at the time of diagnosis. Since most of these tumors originate in the metaphysis and expand circumferentially, the physis is often at risk. When the physis must be sacrificed along with the tumor mass, reconstruction must plan to resolve or prevent significant limb length discrepancy resulting from growth. In lower extremities, this is usually agreed to be a limb length discrepancy of greater than $2 \mathrm{~cm}$ at maturity, but is less defined in the upper extremity. A variety of options exist, and the appropriate choice is often a subject of controversy. Reconstruction strategies include leaving the operative extremity longer than the contralateral side to allow growth, slowing or halting the growth of the nonoperative limb, replacing the defect with an implant that can be expanded as the child grows, or choosing a functional amputation, such as Van Ness rotationplasty (Fig. 6).

In our institution, we have found success with a physeal sparing resection with allograft reconstruction when possible (Fig. 7). This technique has been recently reported in a series of 35 Argentinean patients with 95\% survival of the limb at 5 and 10 years [108]. When the physis cannot be preserved, we prefer modulated growth for defects of less than $3 \mathrm{~cm}$ and an expandable prosthesis for larger defects. Several expandable implants exist on the market. Some require minimal surgery for mechanical expansion, while others rely on an electromagnet for noninvasive lengthening. The noninvasive implants have the advantage of avoiding further surgery, but the first generation has had an intolerable failure rate [109, 110]. Second-generation noninvasive implants have only been available for a short time, but may be more stable. Most expandable prostheses will eventually have to undergo revision, given the age and activity level of their patients. Rotationplasty remains a useful and lasting option in patients with distal femur OS, especially for patients who desire high-demand activity, but few patients and their parents are comfortable with this type of amputation [111].

OS in axial locations is rare, but often presents unique challenges. Pelvis OS accounts for only about $8 \%$ of all cases, but these tumors tend to be larger, more biologically active, and have metastatic disease more often compared to extremity OS [112, 113]. Resection is still necessary for cure, but is more complicated given the three-dimensional anatomy of the bony pelvis and surrounding vital structures. Reconstruction is also more difficult and should only be attempted in certain cases, as many reconstructions only increase the complication rate without improving postoperative function $[114,115]$. In addition to surgery, radiotherapy can be used for added local control and may improve overall survival [116]. OS of the spine is rare as well but, when present, usually occurs in the vertebral body and requires en-bloc 

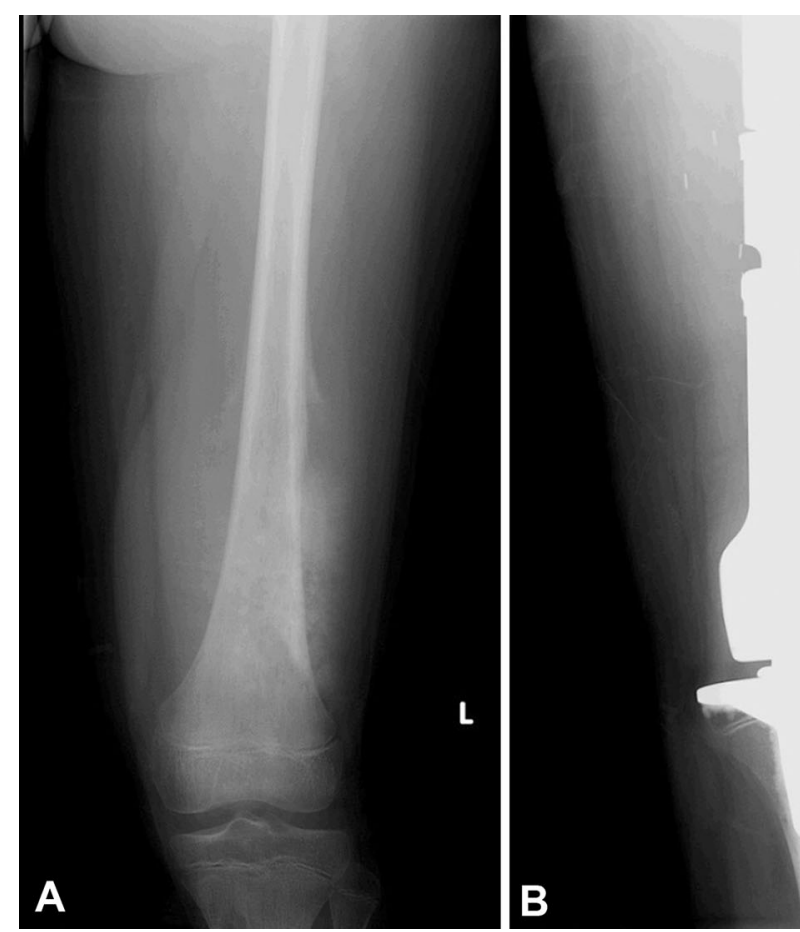

Fig. 6 An 11-year-old male patient with a large osteosarcoma of the distal femur that was reconstructed with an expandable endoprosthesis. Preop (a), immediate postop

resection for cure [117]. OS metastases, when present, should be removed in close chronology to the main tumor. Although lung metastasis predicts a poorer prognosis, resection of metastatic disease can still lead to remission in some cases and has been shown to improve survival [118, 119].

Following completion of treatment, patients with OS must be observed closely for signs of recurrence. The National Comprehensive Cancer Network (NCCN) recommends imaging of both the chest and the surgical site as often as every 3 months during the first 2 years, and continued surveillance at increasing intervals thereafter [67]. Recurrence, either local or distant, was found to occur in 20-30\% of patients who presented with localized disease and $80 \%$ of patients who presented with metastasis within the first 3 years [120]. Recurrent OS is treated with second-line
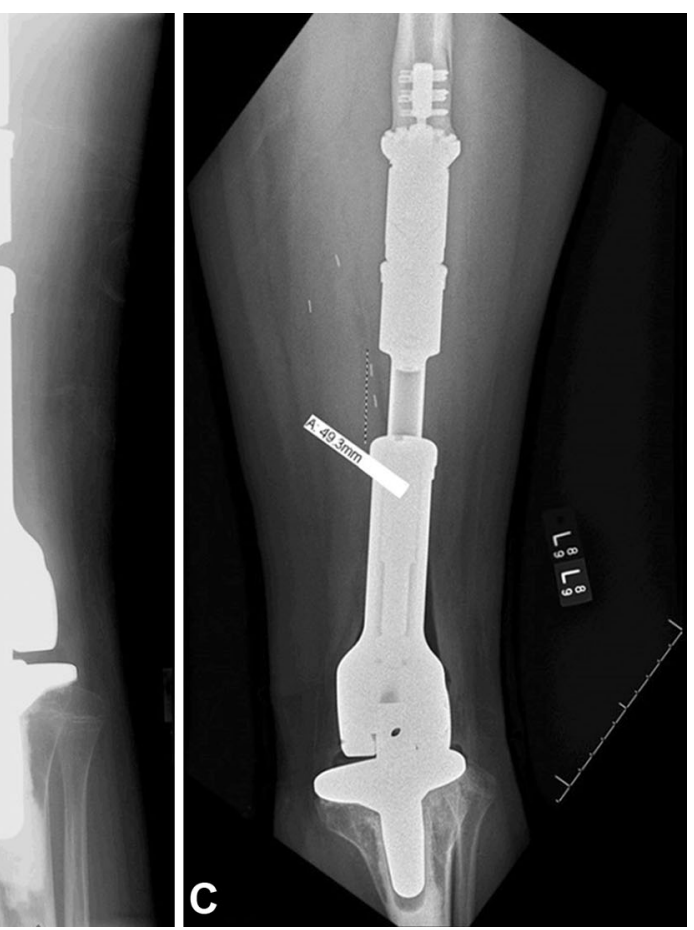

(b), and 2-year postoperative (c) X-ray images are shown. A lengthening of almost $5 \mathrm{~cm}$ was achieved with the expandable construct by age 13

chemotherapy and surgery. If the recurrence can be completely surgically removed, the patient has a greatly increased chance of survival [121].

\section{Prognosis}

Survival rates for patients with OS increased dramatically with the introduction of chemotherapy, but have since plateaued. Today, 5-year survival for all patient groups with high-grade OS is $60-66 \%$ but remains highly dependent on stage at diagnosis. Patients with localized disease can expect 5 -year survival rates as high as 60-78\%, but survival drops to $20-30 \%$ for those with metastatic disease $[66,78,92,101,122]$. Other poor predictors of survival are increased tumor size, increased serum alkaline phosphatase, axial location, and secondary OS [102]. 

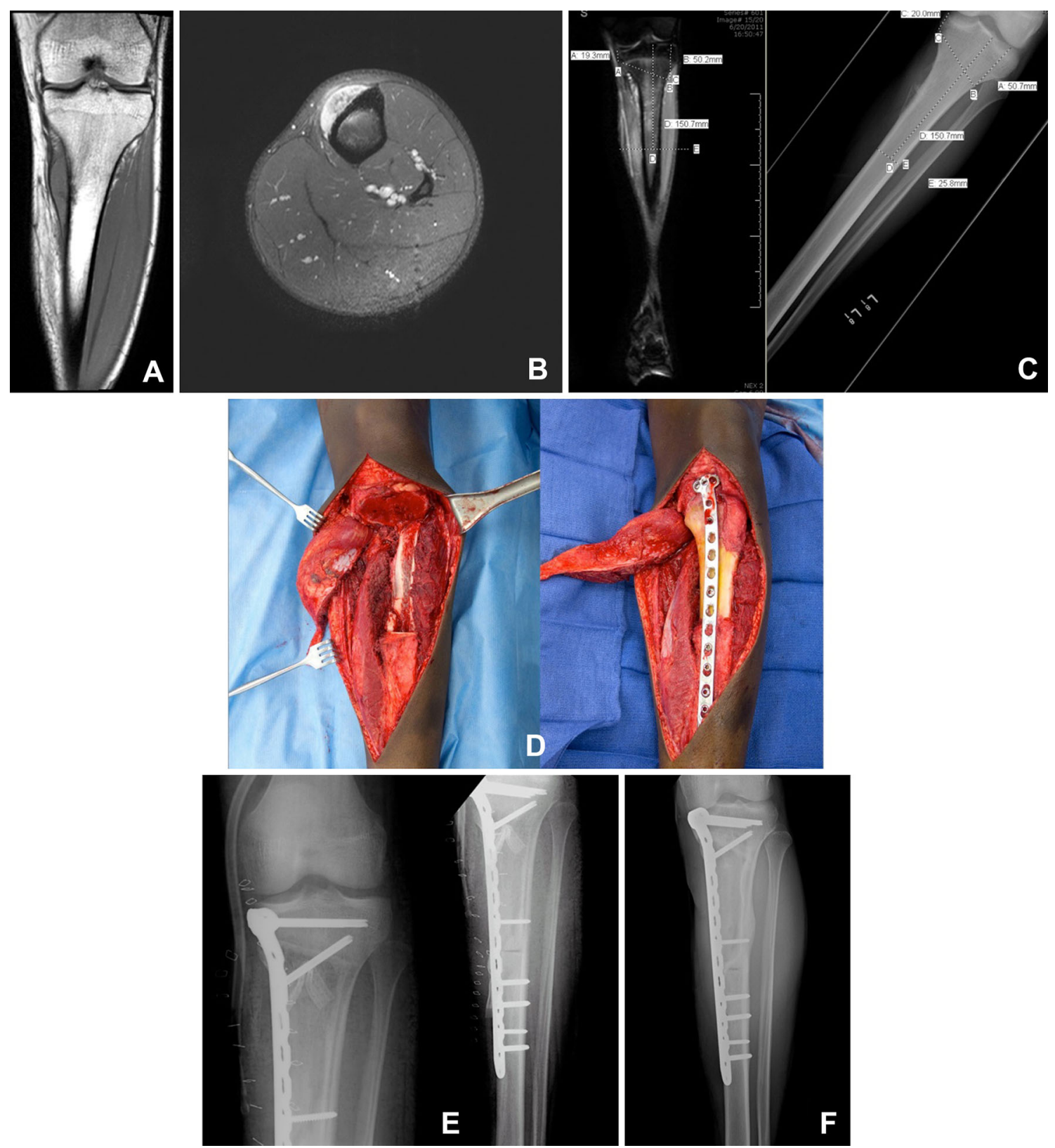

Fig. 7 17-year-old male with periosteal osteosarcoma. MRI images (a, b) show the cortically based tumor is located in the metaphysis with some invasion of the marrow and a soft-tissue mass. A polyhedral, metaphysis-sparing bone cut was planned with navigation

Advanced adult age is associated with increases in both higher-grade tumors and axial tumors, along with decreased response to and toleration of chemotherapy. Subsequently, older adults have a poorer prognosis [123]. Recurrent software (c), and intraoperative guidance was used to assist with the bone cuts according to the preoperative plan (d). A matching allograft was used to fill the defect and fixed to the patient's remaining bone (e). Two-year follow-up shows robust union at the junction sites $(\mathbf{f})$

disease, either local or distant, decreases average 5 -year survival to $20 \%$, but can be as high as $45 \%$ for relapses greater than 2 years out that can be surgically resected. Lower-grade osteosarcomas, including parosteal and 
periosteal sarcomas, have a much better prognosis than the high-grade conventional type. The 5-year survival of periosteal sarcoma is around $83 \%$, and parosteal sarcoma has a reported 5-year survival of $91 \%$. This is primarily due to the low rate of metastasis.

\section{New Therapies}

A number of preclinical and clinical agents are currently being investigated for OS. One area of significant research involves using specific agents to target known processes important in OS pathogenesis. One attractive target is the mTOR pathway, a downstream pathway of IGF-1 that stimulates proliferation, survival, and angiogenesis. Sirolimus, an mTOR inhibitor, was found to inhibit metastasis and OS xenograft growth in mice [124, 125]. Everolimus, an oral mTOR inhibitor, also showed activity against human and mice OS cells, an effect that was enhanced by combination with zoledronic acid [126]. A recent phase I trial has shown that oral everolimus is safe in pediatric populations [127], and a phase II study is currently ongoing in refractory OS [128]. Disruption of angiogenesis is another strategy, and several targeted agents have been tested in OS. Pazopanib is an inhibitor of VEGFR, PDGFR, and c-kit that has shown some efficacy in metastatic OS [129]. The drug is well tolerated in children and currently under investigation in a phase II clinical trial among OS patients with lung metastases. Sorafenib is an oral anti-angiogenic agent with activity against VEGFR-2 and PDFGR-B that has shown good activity as a second- or third-line agent in refractory OS [130]. Surprisingly, a recent clinical study failed to show efficacy when sorafenib was combined with everolimus in inoperable high-grade progressive OS patients [131].

Immune modulation is another area of increased OS research. As discussed earlier, inhibition of the Fas pathway helps OS cells avoid apoptosis and immune-mediated destruction [43]. Targeting this pathway has successfully been accomplished in preclinical models with the use of interleukin 12 (IL-12). IL-12 functions to activate Fas on cell surfaces, leading to increased cell death and immune clearance $[42,44]$. Unfortunately, IL-12 is toxic when administered systemically. Liposomal muramyl tripeptide phosphatidyl ethanolamine (liposomal MTP-PE) is a promising agent that functions to induce endogenous IL-12 and thus provides the effect of IL-12 without the toxicity. In a recent Children's Oncology Group (COG) phase III trial, liposomal MTP-PE improved overall survival regardless of treatment regimen $[45,132]$.

Another class of drugs currently garnering attention in OS are bisphosphonates. Besides their effects on osteoclast activity, bisphosphonates also act to inhibit cell growth and proliferation, can induce apoptosis, and downregulate angiogenic growth factors [133]. In a preclinical study, zoledronate successfully suppressed tumor growth and lung metastasis in a mouse model and is now the subject of an ongoing trial with combination chemotherapy $[126,133]$. In recent years, an international collaboration, the EURAMOS group, has been successful at overcoming the small numbers of patients at each institution by designing cooperative randomized trials across institutions, and even nations. The first phase, EURAMOS-1, tested the addition of pegylated interferon to chemotherapy as maintenance therapy in good responders, and, while the treatment was unsuccessful, the trial showed that international collaboration is possible in this rare tumor $[86,134]$.

The field of pharmacogenetics seeks to predict response to therapy and prognosis, and 
is being used to personalize treatment across healthcare. Recently, Caronia et al. used single nucleotide polymorphisms (SNPs) to identify four variations in two genes responsible for chemotherapy resistance. Their work identified polymorphisms in the $A B C C 3$ gene, a member of the multi-drug resistance protein family, and $A B C B 1$, which encodes for an ATP-mediated efflux pump. Patients with these polymorphisms had inferior estimated 5-year survival [135]. Other authors have used similar techniques to describe variations in different genes leading to changes in prognosis or resistance to chemotherapy $[136,137]$. As this field evolves, new information about a patient's genetic profile can be used to select the most efficacious therapy, minimize side effects, and better inform prognosis.

\section{CONCLUSION}

Advances in chemotherapy and surgery have taken OS from an almost universally fatal disease to one in which the majority of patients will survive with a meaningful quality of life. Despite this, a fair number of those affected will still develop fatal metastatic disease or serious complications of treatment, emphasizing the need for further clinical advancements. Accurate and efficient diagnosis, preoperative chemotherapy, surgical resection, postoperative chemotherapy, and lifelong surveillance are all vital in managing this complicated and potentially deadly disease.

\section{ACKNOWLEDGMENTS}

No funding or sponsorship was received for this study or publication of this article.

All named authors meet the International Committee of Medical Journal Editors
(ICMJE) criteria for authorship for this manuscript, take responsibility for the integrity of the work as a whole, and have given final approval for the version to be published.

All tables/figures are original and have been produced by the authors for this particular publication.

Disclosures. R. A. Durfee, M. Mohammed and $\mathrm{H}$. H. Luu have nothing to disclose.

Compliance with Ethics Guidelines. This article is based on previously conducted studies and does not involve any new studies of human or animal subjects performed by any of the authors.

Open Access. This article is distributed under the terms of the Creative Commons Attribution-NonCommercial 4.0 International License (http://creativecommons.org/licenses/ by-nc/4.0/), which permits any noncommercial use, distribution, and reproduction in any medium, provided you give appropriate credit to the original author(s) and the source, provide a link to the Creative Commons license, and indicate if changes were made.

\section{REFERENCES}

1. Campanacci M. Bone and soft tissue tumors: clinical features, imaging, pathology and treatment. Berlin: Springer; 2013.

2. Sissons HA. The WHO classification of bone tumors. Recent Res Cancer Res. 1976;54:104-8.

3. Damron TA, Ward WG, Stewart A. Osteosarcoma, chondrosarcoma, and Ewing's sarcoma: National Cancer Data Base Report. Clin Orthop Relat Res. 2007;459:40-7.

4. Dorfman HD, Czerniak B. Bone cancers. Cancer. 1995;75(1 Suppl):203-10. 
5. dos Santos Silva I, Swerdlow AJ. Sex differences in the risks of hormone-dependent cancers. Am J Epidemiol. 1993;138(1):10-28.

6. Mirabello L, Troisi RJ, Savage SA. Osteosarcoma incidence and survival rates from 1973 to 2004: data from the Surveillance, Epidemiology, and End Results Program. Cancer. 2009;115(7):1531-43.

7. Fraumeni JF Jr. Stature and malignant tumors of bone in childhood and adolescence. Cancer. 1967;20(6):967-73.

8. Miller RW. Contrasting epidemiology of childhood osteosarcoma, Ewing's tumor, and rhabdomyosarcoma. Natl Cancer Inst Monogr. 1981;56:9-15.

9. Temple HT, Scully SP, O'Keefe RJ, Katapurum S, Mankin HJ. Clinical outcome of 38 patients with juxtacortical osteosarcoma. Clin Orthop Relat Res. 2000;373:208-17.

10. Mirabello L, Troisi RJ, Savage SA. International osteosarcoma incidence patterns in children and adolescents, middle ages and elderly persons. Int J Cancer. 2009;125(1):229-34.

11. Kruzelock RP, Murphy EC, Strong LC, Naylor SL, Hansen MF. Localization of a novel tumor suppressor locus on human chromosome $3 \mathrm{q}$ important in osteosarcoma tumorigenesis. Cancer Res. 1997;57(1):106-9.

12. Nellissery MJ, Padalecki SS, Brkanac Z, et al. Evidence for a novel osteosarcoma tumor-suppressor gene in the chromosome 18 region genetically linked with Paget disease of bone. Am J Hum Genet. 1998;63(3):817-24.

13. Toguchida J, Ishizaki K, Sasaki MS, et al. Preferential mutation of paternally derived RB gene as the initial event in sporadic osteosarcoma. Nature. 1989;338(6211):156-8.

14. Beckerman R, Prives C. Transcriptional regulation by p53. Cold Spring Harb Perspect Biol. 2010;2(8):a000935.

15. Zhang J, Walsh MF, Wu G, et al. Germline mutations in predisposition genes in pediatric cancer. N Engl J Med. 2015;373(24):2336-46.

16. Bougeard G, Renaux-Petel M, Flaman JM, et al. Revisiting Li-Fraumeni syndrome from TP53 mutation carriers. J Clin Oncol. $2015 ; 33(21): 2345-52$.

17. Lonardo F, Ueda T, Huvos AG, Healey J, Ladanyi M. p53 and MDM2 alterations in osteosarcomas: correlation with clinicopathologic features and proliferative rate. Cancer. 1997;79(8):1541-7.
18. Goodrich DW, Wang NP, Qian YW, Lee EY, Lee WH. The retinoblastoma gene product regulates progression through the G1 phase of the cell cycle. Cell. 1991;67(2):293-302.

19. DerKinderen DJ, Koten JW, Nagelkerke NJ, Tan KE, Beemer FA, Den Otter W. Non-ocular cancer in patients with hereditary retinoblastoma and their relatives. Int J Cancer. 1988;41(4):499-504.

20. Kleinerman RA, Schonfeld SJ, Tucker MA. Sarcomas in hereditary retinoblastoma. Clin Sarcoma Res. 2012;2(1):15.

21. Wong FL, Boice JD Jr, Abramson DH, et al. Cancer incidence after retinoblastoma. Radiation dose and sarcoma risk. JAMA. 1997;278(15):1262-7.

22. Hawkins MM, Draper GJ, Kingston JE. Incidence of second primary tumours among childhood cancer survivors. Br J Cancer. 1987;56(3):339-47.

23. Feugeas $\mathrm{O}$, Guriec N, Babin-Boilletot A, et al. Loss of heterozygosity of the RB gene is a poor prognostic factor in patients with osteosarcoma. J Clin Oncol. 1996;14(2):467-72.

24. Wadayama B, Toguchida J, Shimizu T, et al. Mutation spectrum of the retinoblastoma gene in osteosarcomas. Cancer Res. 1994;54(11):3042-8.

25. Nevins JR. The Rb/E2F pathway and cancer. Hum Mol Genet. 2001;10(7):699-703.

26. Nielsen GP, Burns KL, Rosenberg AE, Louis DN. CDKN2A gene deletions and loss of p16 expression occur in osteosarcomas that lack RB alterations. Am J Pathol. 1998;153(1):159-63.

27. Chakraverty RK, Hickson ID. Defending genome integrity during DNA replication: a proposed role for RecQ family helicases. Bioessays. 1999;21(4):286-94.

28. Karow JK, Wu L, Hickson ID. RecQ family helicases: roles in cancer and aging. Curr Opin Genet Dev. 2000;10(1):32-8.

29. Mohaghegh P, Hickson ID. DNA helicase deficiencies associated with cancer predisposition and premature ageing disorders. Hum Mol Genet. 2001;10(7):741-6.

30. Kloen P, Gebhardt MC, Perez-Atayde A, et al. Expression of transforming growth factor-beta (TGF-beta) isoforms in osteosarcomas: TGF-beta3 is related to disease progression. Cancer. 1997;80(12):2230-9.

31. Assoian RK, Komoriya A, Meyers CA, Miller DM, Sporn MB. Transforming growth factor-beta in human platelets. Identification of a major storage 
site, purification, and characterization. J Biol Chem. 1983;258(11):7155-60.

32. Kloen P, Jennings CL, Gebhardt MC, Springfield DS, Mankin HJ. Expression of transforming growth factor-beta (TGF-beta) receptors, TGF-beta 1 and TGF-beta 2 production and autocrine growth control in osteosarcoma cells. Int $\mathrm{J}$ Cancer. 1994;58(3):440-5.

33. Lamplot JD, Denduluri S, Qin J, et al. The current and future therapies for human osteosarcoma. Curr Cancer Ther Rev. 2013;9(1):55-77.

34. Luther GA, Lamplot J, Chen X, et al. IGFBP5 domains exert distinct inhibitory effects on the tumorigenicity and metastasis of human osteosarcoma. Cancer Lett. 2013;336(1):222-30.

35. Su Y, Wagner ER, Luo Q, et al. Insulin-like growth factor binding protein 5 suppresses tumor growth and metastasis of human osteosarcoma. Oncogene. 2011;30(37):3907-17.

36. Jentzsch T, Robl B, Husmann M, Bode-Lesniewska B, Fuchs B. Worse prognosis of osteosarcoma patients expressing IGF-1 on a tissue microarray. Anticancer Res. 2014;34(8):3881-9.

37. MacEwen EG, Pastor J, Kutzke J, et al. IGF-1 receptor contributes to the malignant phenotype in human and canine osteosarcoma. J Cell Biochem. 2004;92(1):77-91.

38. Burrow S, Andrulis IL, Pollak M, Bell RS. Expression of insulin-like growth factor receptor, IGF-1, and IGF-2 in primary and metastatic osteosarcoma. J Surg Oncol. 1998;69(1):21-7.

39. Chen G, Fang T, Huang Z, et al. MicroRNA-133a inhibits osteosarcoma cells proliferation and invasion via targeting IGF-1R. Cell Physiol Biochem. 2016;38(2):598-608.

40. Kappel CC, Velez-Yanguas MC, Hirschfeld S, Helman LJ. Human osteosarcoma cell lines are dependent on insulin-like growth factor I for in vitro growth. Cancer Res. 1994;54(10):2803-7.

41. Heymann D, Redini F. Targeted therapies for bone sarcomas. Bonekey Rep. 2013;2:378.

42. Lafleur EA, Koshkina NV, Stewart J, et al. Increased Fas expression reduces the metastatic potential of human osteosarcoma cells. Clin Cancer Res. 2004;10(23):8114-9.

43. Worth LL, Lafleur EA, Jia SF, Kleinerman ES. Fas expression inversely correlates with metastatic potential in osteosarcoma cells. Oncol Rep. 2002;9(4):823-7.
44. Lafleur EA, Jia SF, Worth LL, Zhou Z, Owen-Schaub LB, Kleinerman ES. Interleukin (IL)-12 and IL-12 gene transfer up-regulate Fas expression in human osteosarcoma and breast cancer cells. Cancer Res. 2001;61(10):4066-71.

45. PosthumaDeBoer J, Witlox MA, Kaspers GJ, van Royen BJ. Molecular alterations as target for therapy in metastatic osteosarcoma: a review of literature. Clin Exp Metastasis. 2011;28(5):493-503.

46. Hingorani P, Zhang W, Gorlick R, Kolb EA. Inhibition of Src phosphorylation alters metastatic potential of osteosarcoma in vitro but not in vivo. Clin Cancer Res. 2009;15(10):3416-22.

47. Kim LC, Song L, Haura EB. Src kinases as therapeutic targets for cancer. Nat Rev Clin Oncol. 2009;6(10):587-95.

48. Savage SA, Mirabello L, Wang Z, et al. Genome-wide association study identifies two susceptibility loci for osteosarcoma. Nat Genet. 2013;45(7):799-803.

49. Mirabello L, Koster R, Moriarity BS, et al. A genome-wide scan identifies variants in NFIB associated with metastasis in patients with osteosarcoma. Cancer Discov. 2015;5(9):920-31.

50. Desai P, Perino G, Present D, Steiner GC. Sarcoma in association with bone infarcts. Report of five cases. Arch Pathol Lab Med. 1996;120(5):482-9.

51. Hansen MF, Seton M, Merchant A. Osteosarcoma in Paget's disease of bone. J Bone Miner Res. 2006;21(Suppl 2):P58-63.

52. Shaheen M, Deheshi BM, Riad S, et al. Prognosis of radiation-induced bone sarcoma is similar to primary osteosarcoma. Clin Orthop Relat Res. 2006;450:76-81.

53. Spina V, Montanari N, Romagnoli R. Malignant tumors of the osteogenic matrix. Eur J Radiol. 1998;27(Suppl 1):S98-109.

54. Fox MG, Trotta BM. Osteosarcoma: review of the various types with emphasis on recent advancements in imaging. Semin Musculoskelet Radiol. 2013;17(2):123-36.

55. Klein MJ, Siegal GP. Osteosarcoma: anatomic and histologic variants. Am J Clin Pathol. 2006;125(4):555-81.

56. Clayer M. Many faces of osteosarcoma on plain radiographs. ANZ J Surg. 2015;85(1-2):22-6.

57. Grimer RJ, Bielack S, Flege S, et al. Periosteal osteosarcoma-a European review of outcome. Eur J Cancer. 2005;41(18):2806-11. 
58. Scully SP, Ghert MA, Zurakowski D, Thompson RC, Gebhardt MC. Pathologic fracture in osteosarcoma: prognostic importance and treatment implications. J Bone Jt Surg Am. 2002;84-A(1):49-57.

59. Dadia S, Grimer R. Characteristics, diagnosis and treatment of bone and soft tissue sarcomas. Br J Hosp Med (Lond). 2007;68(11):589-93.

60. Chen J, Sun MX, Hua YQ, Cai ZD. Prognostic significance of serum lactate dehydrogenase level in osteosarcoma: a meta-analysis. J Cancer Res Clin Oncol. 2014;140(7):1205-10.

61. Marais LC, Bertie J, Rodseth R, Sartorius B, Ferreira N. Pre-treatment serum lactate dehydrogenase and alkaline phosphatase as predictors of metastases in extremity osteosarcoma. J Bone Oncol. 2015;4(3): 80-4.

62. Ren HY, Sun LL, Li HY, Ye ZM. Prognostic significance of serum alkaline phosphatase level in osteosarcoma: a meta-analysis of published data. Biomed Res Int. 2015;2015:160835.

63. Vasquez L, Tarrillo F, Oscanoa M, et al. Analysis of prognostic factors in high-grade osteosarcoma of the extremities in children: a 15-year single-institution experience. Front Oncol. 2016;6:22.

64. Mankin HJ, Mankin CJ, Simon MA. The hazards of the biopsy, revisited. Members of the Musculoskeletal Tumor Society. J Bone Jt Surg Am. 1996;78(5):656-63.

65. Binitie O, Tejiram S, Conway S, Cheong D, Temple HT, Letson GD. Adult soft tissue sarcoma local recurrence after adjuvant treatment without resection of core needle biopsy tract. Clin Orthop Relat Res. 2013;471(3):891-8.

66. Isakoff MS, Bielack SS, Meltzer P, Gorlick R. Osteosarcoma: current treatment and a collaborative pathway to success. J Clin Oncol. 2015;33(27):3029-35.

67. Biermann JS, Adkins DR, Agulnik M, Benjamin RS, Brigman B, et al. NCCN guidelines version 1.2013. Bone cancer. Fort Washington: NCCN; 2012. p. 58.

68. Kager L, Zoubek A, Potschger U, et al. Primary metastatic osteosarcoma: presentation and outcome of patients treated on neoadjuvant Cooperative Osteosarcoma Study Group protocols. J Clin Oncol. 2003;21(10):2011-8.

69. Link MP, Goorin AM, Miser AW, et al. The effect of adjuvant chemotherapy on relapse-free survival in patients with osteosarcoma of the extremity. N Engl J Med. 1986;314(25):1600-6.
70. Yonemoto T, Tatezaki S, Ishii T, Satoh T, Kimura H, Iwai N. Prognosis of osteosarcoma with pulmonary metastases at initial presentation is not dismal. Clin Orthop Relat Res. 1998;349:194-9.

71. Kaste SC, Pratt CB, Cain AM, Jones-Wallace DJ, Rao $\mathrm{BN}$. Metastases detected at the time of diagnosis of primary pediatric extremity osteosarcoma at diagnosis: imaging features. Cancer. 1999;86(8): 1602-8.

72. Eary JF, Mankoff DA. Tumor metabolic rates in sarcoma using FDG PET. J Nucl Med. 1998;39(2):250-4.

73. Eary JF, O'Sullivan F, Powitan Y, et al. Sarcoma tumor FDG uptake measured by PET and patient outcome: a retrospective analysis. Eur J Nucl Med Mol Imaging. 2002;29(9):1149-54.

74. Kager L, Zoubek A, Kastner U, et al. Skip metastases in osteosarcoma: experience of the Cooperative Osteosarcoma Study Group. J Clin Oncol. 2006;24(10):1535-41.

75. Moore DD, Luu HH. Osteosarcoma. Cancer Treat Res. 2014;162:65-92.

76. Jaffe N. Recent advances in the chemotherapy of metastatic osteogenic sarcoma. Cancer. 1972;30(6):1627-31.

77. Rosen G, Caparros B, Huvos AG, et al. Preoperative chemotherapy for osteogenic sarcoma: selection of postoperative adjuvant chemotherapy based on the response of the primary tumor to preoperative chemotherapy. Cancer. 1982;49(6):1221-30.

78. Friebele JC, Peck J, Pan X, Abdel-Rasoul M, Mayerson JL. Osteosarcoma: a meta-analysis and review of the literature. Am J Orthop (Belle Mead NJ). 2015;44(12):547-53.

79. Ferrari S, Serra M. An update on chemotherapy for osteosarcoma. Expert Opin Pharmacother. 2015;16(18):2727-36.

80. Bielack S, Jurgens H, Jundt G, et al. Osteosarcoma: the COSS experience. Cancer Treat Res. 2009; 152:289-308.

81. Carrle D, Bielack SS. Current strategies of chemotherapy in osteosarcoma. Int Orthop. 2006;30(6):445-51.

82. Ferrari S, Ruggieri P, Cefalo G, et al. Neoadjuvant chemotherapy with methotrexate, cisplatin, and doxorubicin with or without ifosfamide in nonmetastatic osteosarcoma of the extremity: an Italian Sarcoma Group trial ISG/OS-1. J Clin Oncol. 2012;30(17):2112-8. 
83. Schwartz CL, Wexler LH, Krailo MD, et al. Intensified chemotherapy with dexrazoxane cardioprotection in newly diagnosed nonmetastatic osteosarcoma: a report from the Children's Oncology Group. Pediatr Blood Cancer. 2016;63(1):54-61.

84. Wang WG, Wan C, Liao GJ. The efficacy of high-dose versus moderate-dose chemotherapy in treating osteosarcoma: a systematic review and meta-analysis. Int J Clin Exp Med. 2015;8(9):15967-74.

85. Anninga JK, Gelderblom H, Fiocco $M$, et al. Chemotherapeutic adjuvant treatment for osteosarcoma: where do we stand? Eur J Cancer. 2011;47(16):2431-45.

86. Bielack SS, Smeland S, Whelan JS, et al. Methotrexate, doxorubicin, and cisplatin (MAP) plus maintenance pegylated interferon Alfa-2b versus MAP alone in patients with resectable high-grade osteosarcoma and good histologic response to preoperative MAP: first results of the EURAMOS-1 good response randomized controlled trial. J Clin Oncol. 2015;33(20):2279-87.

87. He H, Ni J, Huang J. Molecular mechanisms of chemoresistance in osteosarcoma (review). Oncol Lett. 2014;7(5):1352-62.

88. Hang JF, Chen PC. Parosteal osteosarcoma. Arch Pathol Lab Med. 2014;138(5):694-9.

89. Mavrogenis AF, Rossi G, Palmerini E, et al. Palliative treatments for advanced osteosarcoma. J BUON. 2012;17(3):436-45.

90. Oertel S, Blattmann C, Rieken S, et al. Radiotherapy in the treatment of primary osteosarcoma-a single center experience. Tumori. 2010;96(4):582-8.

91. DeLaney TF, Park L, Goldberg SI, et al. Radiotherapy for local control of osteosarcoma. Int J Radiat Oncol Biol Phys. 2005;61(2):492-8.

92. Bacci G, Longhi A, Versari M, Mercuri M, Briccoli A, Picci P. Prognostic factors for osteosarcoma of the extremity treated with neoadjuvant chemotherapy: 15-year experience in 789 patients treated at a single institution. Cancer. 2006;106(5):1154-61.

93. Bacci G, Longhi A, Bertoni F, et al. Bone metastases in osteosarcoma patients treated with neoadjuvant or adjuvant chemotherapy: the Rizzoli experience in 52 patients. Acta Orthop. 2006;77(6):938-43.

94. Grimer RJ. Surgical options for children with osteosarcoma. Lancet Oncol. 2005;6(2):85-92.
95. Marulanda GA, Henderson ER, Johnson DA, Letson GD, Cheong D. Orthopedic surgery options for the treatment of primary osteosarcoma. Cancer Control. 2008;15(1):13-20.

96. Bacci G, Ferrari S, Lari S, et al. Osteosarcoma of the limb. Amputation or limb salvage in patients treated by neoadjuvant chemotherapy. J Bone Jt Surg Brit. 2002;84(1):88-92.

97. Rougraff BT, Simon MA, Kneisl JS, Greenberg DB, Mankin HJ. Limb salvage compared with amputation for osteosarcoma of the distal end of the femur. A long-term oncological, functional, and quality-of-life study. J Bone Jt Surg Am. 1994;76(5):649-56.

98. Simon MA. Limb salvage for osteosarcoma in the 1980s. Clin Orthop Relat Res. 1991;270:264-70.

99. Simon MA, Aschliman MA, Thomas N, Mankin HJ. Limb-salvage treatment versus amputation for osteosarcoma of the distal end of the femur. J Bone Jt Surg Am Vol. 1986;68(9):1331-7.

100. Li X, Zhang Y, Wan S, et al. A comparative study between limb-salvage and amputation for treating osteosarcoma. J Bone Oncol. 2016;5(1):15-21.

101. Haddox CL, Han G, Anijar L, et al. Osteosarcoma in pediatric patients and young adults: a single institution retrospective review of presentation, therapy, and outcome. Sarcoma. 2014;2014:402509.

102. Bielack SS, Kempf-Bielack B, Delling G, et al. Prognostic factors in high-grade osteosarcoma of the extremities or trunk: an analysis of 1702 patients treated on neoadjuvant cooperative osteosarcoma study group protocols. J Clin Oncol. 2002;20(3):776-90.

103. Jeys LM, Kulkarni A, Grimer RJ, Carter SR, Tillman RM, Abudu A. Endoprosthetic reconstruction for the treatment of musculoskeletal tumors of the appendicular skeleton and pelvis. J Bone Jt Surg Am Vol. 2008;90(6):1265-71.

104. Grimer RJ, Aydin BK, Wafa H, et al. Very long-term outcomes after endoprosthetic replacement for malignant tumours of bone. Bone Jt J. 2016;98-B(6):857-64.

105. Mankin HJ, Gebhardt MC, Jennings LC, Springfield DS, Tomford WW. Long-term results of allograft replacement in the management of bone tumors. Clin Orthop Relat Res. 1996;324:86-97.

106. Campanacci L, Manfrini M, Colangeli M, Ali N, Mercuri M. Long-term results in children with massive bone osteoarticular allografts of the knee 
for high-grade osteosarcoma. J Pediatr Orthop. 2010;30(8):919-27.

107. Campanacci L, Ali N, Casanova JM, Kreshak J, Manfrini M. Resurfaced allograft-prosthetic composite for proximal tibial reconstruction in children: intermediate-term results of an original technique. J Bone Jt Surg Am Vol. 2015;97(3):241-50.

108. Aponte-Tinao L, Ayerza MA, Muscolo DL, Farfalli GL. Survival, recurrence, and function after epiphyseal preservation and allograft reconstruction in osteosarcoma of the knee. Clin Orthop Relat Res. 2015;473(5):1789-96.

109. Benevenia J, Patterson F, Beebe K, et al. Results of 20 consecutive patients treated with the Repiphysis expandable prosthesis for primary malignant bone. SpringerPlus. 2015;4:793.

110. Staals EL, Colangeli M, Ali N, Casanova JM, Donati DM, Manfrini M. Are complications associated with the repiphysis (R) expandable distal femoral prosthesis acceptable for its continued use? Clin Orthop Relat Res. 2015;473(9):3003-13.

111. Gradl G, Postl LK, Lenze U, et al. Long-term functional outcome and quality of life following rotationplasty for treatment of malignant tumors. BMC Musculoskelet Disord. 2015;16:262.

112. Parry MC, Laitinen M, Albergo J, et al. Osteosarcoma of the pelvis. Bone Jt J. 2016;98-B(4):555-63.

113. Isakoff MS, Barkauskas DA, Ebb D, Morris C, Letson GD. Poor survival for osteosarcoma of the pelvis: a report from the Children's Oncology Group. Clin Orthop Relat Res. 2012;470(7):2007-13.

114. Farfalli GL, Albergo JI, Ritacco LE, Ayerza MA, Muscolo DL, Aponte-Tinao LA. Oncologic and clinical outcomes in pelvic primary bone sarcomas treated with limb salvage surgery. Musculoskelet Surg. 2015;99(3):237-42.

115. Mayerson JL, Wooldridge AN, Scharschmidt TJ. Pelvic resection: current concepts. J Am Acad Orthop Surg. 2014;22(4):214-22.

116. Ozaki T, Flege S, Kevric M, et al. Osteosarcoma of the pelvis: experience of the Cooperative Osteosarcoma Study Group. J Clin Oncol. 2003;21(2):334-41.

117. Dekutoski MB, Clarke MJ, Rose $P$, et al. Osteosarcoma of the spine: prognostic variables for local recurrence and overall survival, a multicenter ambispective study. J Neurosurg Spine. 2016;25(1):59-68.
118. Gok Durnali A, Paksoy Turkoz F, Ardic Yukruk F, et al. Outcomes of adolescent and adult patients with lung metastatic osteosarcoma and comparison of synchronous and metachronous lung metastatic groups. PLoS One. 2016;11(5):e0152621.

119. Bacci G, Rocca M, Salone $M$, et al. High grade osteosarcoma of the extremities with lung metastases at presentation: treatment with neoadjuvant chemotherapy and simultaneous resection of primary and metastatic lesions. J Surg Oncol. 2008;98(6):415-20.

120. Longhi A, Errani C, De Paolis M, Mercuri M, Bacci G. Primary bone osteosarcoma in the pediatric age: state of the art. Cancer Treat Rev. 2006;32(6):423-36.

121. Kempf-Bielack B, Bielack SS, Jurgens $H$, et al. Osteosarcoma relapse after combined modality therapy: an analysis of unselected patients in the Cooperative Osteosarcoma Study Group (COSS). J Clin Oncol. 2005;23(3):559-68.

122. Smith MA, Seibel NL, Altekruse SF, et al. Outcomes for children and adolescents with cancer: challenges for the twenty-first century. J Clin Oncol. 2010;28(15):2625-34.

123. Grimer RJ, Cannon SR, Taminiau AM, et al. Osteosarcoma over the age of forty. Eur J Cancer. 2003;39(2):157-63.

124. Houghton PJ, Morton CL, Kolb EA, et al. Initial testing (stage 1) of the mTOR inhibitor rapamycin by the pediatric preclinical testing program. Pediatr Blood Cancer. 2008;50(4):799-805.

125. Wan X, Mendoza A, Khanna C, Helman LJ. Rapamycin inhibits ezrin-mediated metastatic behavior in a murine model of osteosarcoma. Cancer Res. 2005;65(6):2406-11.

126. Moriceau G, Ory B, Mitrofan L, et al. Zoledronic acid potentiates $\mathrm{mTOR}$ inhibition and abolishes the resistance of osteosarcoma cells to RAD001 (everolimus): pivotal role of the prenylation process. Cancer Res. 2010;70(24):10329-39.

127. Fouladi M, Laningham F, Wu J, et al. Phase I study of everolimus in pediatric patients with refractory solid tumors. J Clin Oncol. 2007;25(30):4806-12.

128. Hattinger CM, Fanelli M, Tavanti E, et al. Advances in emerging drugs for osteosarcoma. Expert Opin Emerg Drugs. 2015;20(3):495-514.

129. Safwat A, Boysen A, Lucke A, Rossen P. Pazopanib in metastatic osteosarcoma: significant clinical response in three consecutive patients. Acta Oncol. 2014;53(10):1451-4. 
130. Grignani G, Palmerini E, Dileo P, et al. A phase II trial of sorafenib in relapsed and unresectable high-grade osteosarcoma after failure of standard multimodal therapy: an Italian Sarcoma Group study. Ann Oncol. 2012;23(2):508-16.

131. Grignani G, Palmerini E, Ferraresi V, et al. Sorafenib and everolimus for patients with unresectable high-grade osteosarcoma progressing after standard treatment: a non-randomised phase 2 clinical trial. Lancet Oncol. 2015;16(1):98-107.

132. Chou AJ, Kleinerman ES, Krailo MD, et al. Addition of muramyl tripeptide to chemotherapy for patients with newly diagnosed metastatic osteosarcoma: a report from the Children's Oncology Group. Cancer. 2009;115(22):5339-48.

133. Kansara M, Teng MW, Smyth MJ, Thomas DM. Translational biology of osteosarcoma. Nat Rev Cancer. 2014;14(11):722-35.
134. Whelan JS, Bielack SS, Marina N, et al. EURAMOS-1, an international randomised study for osteosarcoma: results from pre-randomisation treatment. Ann Oncol. 2015;26(2):407-14.

135. Caronia D, Patino-Garcia A, Perez-Martinez A, et al. Effect of ABCB1 and ABCC3 polymorphisms on osteosarcoma survival after chemotherapy: a pharmacogenetic study. PLoS One. 2011;6(10):e26091.

136. Hagleitner MM, Coenen MJ, Gelderblom H, et al. A first step toward personalized medicine in osteosarcoma: pharmacogenetics as predictive marker of outcome after chemotherapy-based treatment. Clin Cancer Res. 2015;21(15):3436-41.

137. Hattinger CM, Serra M. Role of pharmacogenetics of drug-metabolizing enzymes in treating osteosarcoma. Expert Opin Drug Metab Toxicol. 2015;11(9):1449-63. 